\title{
Construction and Piloting of Attitude Towards Research Participation Scale for University Students
}

\author{
Khatib Ahmad Khan' \\ Danabekova Aigerim ${ }^{2}$ \\ Zhao Xueqing ${ }^{2}$ \\ Adnan Adil $^{3}$ \\ Saba Ghayas $\mathbb{D}^{3}$ \\ Safia Yasmeen ${ }^{3}$ \\ Kinza Khalid ${ }^{3}$ \\ Ammara Tahir ${ }^{3}$ \\ 'School of Oriental Studies, Xian \\ International Studies University, Xi'an, \\ People's Republic of China; ${ }^{2}$ School of \\ Chinese Language and Literature, Shaanxi \\ Normal University, Xi'an, People's \\ Republic of China; ${ }^{3}$ Department of \\ Psychology, University of Sargodha, \\ Sargodha, Punjab, Pakistan
}

Correspondence: Saba Ghayas Department of Psychology, University of Sargodha, Sargodha, Punjab, Pakistan

Email Saba.ghayas@uos.edu.pk
Introduction: Attitude toward participation in the research plays an important role in the quality of any research. Therefore, researchers aimed at construction and piloting of scale to measure attitude toward research participation for university students.

Method and Results: In Study I, an initial pool of items was generated on the basis of literature review, semi-structured interviews and expert opinions. After ensuring content validity and finalizing items with the help of experts, the scale was applied on a sample of 426 university students including both men $(n=114)$ and women $(n=312)$ with age range of 17-30. Exploratory factor analysis revealed the two factor structure was with $60.33 \%$ cumulative variance. The factors revealed were positive attitude and negative attitude toward research with alpha reliability of 0.84 for positive attitude while 0.76 for negative attitude. In Study II, confirmatory factor analysis revealed excellent model fit indices with two factor structure. Study III was meant to provide evidence of construct validity. Positive correlation showed exploration and curiosity with positive attitude toward research and negative correlation of exploration and curiosity with negative attitude toward research participation provided strong evidence for convergent validity. While non-significant correlation of attitude toward research with religiosity confirmed the divergent validity of the scale.

Conclusion: Findings of the study revealed that Attitude Toward Research Participation Scale is a valid and reliable measure. It can be used for university students to measure their attitude toward research.

Keywords: research attitude, psychometric properties, validity, reliability

\section{Introduction}

Research is the method of collecting and studying facts to enhance our information of the phenomenon. ${ }^{1}$ In today's rapid changing world, research has become one of the most important logical resources for any human being seeking to change his way of life. It opens up new doors to a variety of all fields of life. In reality, research plays a significant role in enormous advancement of human being, which explains its importance in itself. With the increased realization about the significance of research, higher education has emphasized more on writing research papers and students are asked to conduct researches concerning various problems. ${ }^{2}$ The quality of research paper is dependent upon the attitude of researcher and participants' attitude toward participation as a sample in the study. ${ }^{3,4}$ Importance of research and its implications are consistently being proved, nonetheless, many students and researchers are frightened of research, finding it tough or hard. ${ }^{5,6}$

Students' attitude is considered more important in research than their experiences and academic preparation. A positive attitude toward research is a key to 
success and progress in the type of societies that are ready to learn new knowledge to improve their quality of lives. ${ }^{2}$ The attitude toward research essentially approaches an indepth study of questioning, feeling and the person's behavior in the direction of research. It is said that it is crucial to become aware of the attitudes in the direction of research so that a positive mindset can be advanced among university students and consequently their studies can be facilitated in turn. ${ }^{7,8}$ Various researches proved that students are having variety of attitudes toward research; some are understanding its importance, some takes it useless and some understands its importance but consider it tough and boring. ${ }^{2,9-14}$

A lot of reasons are reported by researchers regarding the negative attitudes of individuals toward research. For instance lack of research skills, perceived lack of usefulness of research, research-related difficulties. ${ }^{2,11,15}$ One of the most frequently reported research difficulties is the difficulty in data collection due to the attitude of research participants toward the process of research. Participants' attitude toward research is not properly studied. Participants show concern about data sharing. Attitudes in the direction of data sharing had been distinguished into positive expectations ("hopes") and negative expectancies ("fears"). There have been normally extra hopes associated with information sharing than fears. Positive attitude toward research includes usefulness or benefits of data sharing in research. In a qualitative research three main types of benefits of data sharing in research were identified: benefit to participants or immediate community, benefits to the students or public, and benefits to science or research. ${ }^{16}$ The majority of participants wanted to see if participating in research could help their local community, as one participant put it: "Data sharing is appropriate if the community benefits, there is no point in simply writing about issues". ${ }^{17}$ There should be "local translational benefits" for "the society that contributed", particularly if the research focused on problems faced by community. ${ }^{18,19}$

It is said that participating in research actually is marked with social value and it provides actual benefit to the people. ${ }^{20}$ Many researches were conducted to measure the attitude of students across disciplines toward research. For example, a research study tried to dig out the attitude of postgraduate students toward research. Five constructs had been investigated specifically on the usefulness of research for a career, academic stress, positive attitude toward research, research relevance to life, and research trouble. The results had been as compared between men and woman. The study observed that men had extensively more positive attitudes toward research than the women alongside the ones of the five constructs. ${ }^{21}$ Another study stated that most of the students have negative attitude toward research. ${ }^{4}$ Though students comprehend its usefulness and importance, they find it difficult and demanding toward research. ${ }^{22}$

It is said that the main problem behind negative attitude toward research participation is the desire for privateness/confidentiality. Students have been concerned that records might be "misused", both by accident (misinterpretation) or deliberately, in an effort to touch contributors or control facts to suit a selected cause. ${ }^{19,20}$

Much consideration has been paid to anonymization and information control, but still participants feel hesitation in research participation. Some previous reviews of literature regarding the participants' attitude toward research proves that participants have concerns and preferences regarding research and if it came into the knowledge of researchers or sponsor person that advancement in research field is confirmed because it is participant who contributed in data through which advancement occurs. ${ }^{23}$

Previously few researchers worked on the attitude toward research among students of various disciplines. It was found that positive attitude of students toward research was correlated with tendency to use information resources, academic performance, and curiosity. ${ }^{24}$ Curiosity is considered as a driving force for the research process and its completion. ${ }^{25}$ Though no study has yet explored the relationship of attitude toward research participation and curiosity, literature regarding the role of curiosity in the success of research helps in predicting that experience and attitude of participants about research must have a significant link with the level of curiosity among research participants.

Keeping in view the idea that experiences of research participants are usually taken as granted, previously researchers tried to understand the experiences of research participants. Their findings revealed that participants are experiencing more problems and less benefits for research participation. Their experiences during the research participation determine their attitude toward research participation. ${ }^{26}$ Keeping in view the importance of participants attitude toward research in the successful completion of any research, the current study is meant to construct a scale to measure attitude toward research participation in students. The variable "attitude toward research participation" is very important because it is 
necessary to know about participant's attitude toward research before data collection. As participants attitude toward research heavily effect data which they share with researcher and results which are drawn from it. Literature reveals that scales of attitude toward research exist that measure the attitude of researcher like attitude toward research scale that measure the attitude of those students who are involve in conducting research but there is no such scale that could measure the attitude of students toward research participation. The purpose of this study is to construct and validate the scale of attitude toward research participation in students of Pakistan.

Objectives of the current research were fulfilled in three studies. Study I was meant to construct the scale, while Study II was carried out to confirm the factor structure and Study III provided evidence for the construct validity (convergent $\&$ discriminant) of scale.

\section{Materials and Methods}

\section{Study I: Development of Attitude Toward Research Participation Scale}

\section{Step I}

In first step, in order to generate the item pool, semistructured interviews were conducted with 30 university students. Men and women were given equal representation. Only those students were interviewed who have already participated in any type of research. Ten open ended questions were asked. Data taken through interviews were analyzed and main themes were extracted to generate the item pool. Furthermore by reviewing literature, and consulting expert opinion (3 Lecturers, 5 Assistant Professors, 3 Associate Professors, 1 Professor) an initial pool of item was developed. Initially 24 items were developed that cover the domain of attitude toward research participation. For critical review 24 items were given to experts including 2 Lecturers and 4 Assistant Professors of the Education and Psychology Department. It was mentioned to subject matter expert that attitude toward research participants is taken as feeling, cognitions and the person's behavior in the direction of research participation. Expert finalized 20 items and showed complete agreement on items because of good face and content validity. In the end, items were finalized and written in the form of scale. The 5-point Likert type such as $1=$ never, $2=$ seldom, $3=$ sometime, 4 = often, 5 = always was decided as the response format of Attitude Toward Research Participation Scale. Ethical approval for the study was obtained from Institutional
Review Board, Department of Psychology, and University of Sargodha (PSY332/2021). The IRB approved the topic, mode of informed consent (written), item pool and allowed for research as there was no social, emotional or financial threat to the participants. Study was conducted in accordance with Declaration of Helsinki. After getting ethical approval sample was collected for all the three studies. Step 2: Tryout study. In order to analyze psychometric properties of the 20-item Attitude Toward Research Participation Scale, a tryout study was carried out. The tryout study was also aimed to eliminate the vague, uncertain and double-barreled statements and to confirm accuracy and understandability of items in the scale. The study sample consist of 80 participants including both men $(\mathrm{n}=$ $39)$ and women $(n=41)$ with the age range 17-28 years. Students from social and pure sciences both were given representation in the sample. Students who were admitted in university on the basis of sports or disability quota were excluded from the study. Twenty items were applied to the participants and they were asked to respond and to provide their feedback on all the items. Tryout study was conducted to analyze the viability of items in Attitude Toward Research Participation Scale. Final items were selected for factor analysis. Out of 20, 2 items were removed because the response of all participants was similar on these items. Items on which all participants respond in a similar way should be removed and only those items that can make difference among participants should be selected. $^{25}$ Three items were discarded because participants criticized them to be inappropriate. As a result of tryout study 15 items were finalized for further factor analysis.

\section{Step 3: Dimensionality and Reliability of Attitude Toward Research Participation Scale \\ Sample}

Convenient sampling technique was used to collect data. The study sample consisted of 426 students including both men $(\mathrm{n}=114)$ and women $(\mathrm{n}=312)$ with age range of 17 $30(M=21.8, S D=6.77)$. Sample was selected from various universities of Punjab. Students from social and pure sciences both were given representation in the sample. Students who were admitted in university on the basis of sports or disability quota were excluded from the study.

\section{Factor Analysis}

In order to run factor analysis, 15 items were found suitable and were reserved after the tryout study. On the sample of 426 participants exploratory factor analysis was conducted 
through principle axis factoring by using the oblique rotation method. The reason for using oblique rotation method (direct oblimin) is its capacity to provide enough for factor structure as compared to an orthogonal method. ${ }^{26}$ As a result of analysis well defined, clear, interpretable and theoretically consistent two factors were formed.

\section{Results}

Table 1 shows the results of principle axis factoring by using the direct oblimin method. As it was assumed that factors would be correlated with each other therefore the most suitable rotation method was oblique rotation method (direct oblimin). Value of Kaiser-Meyer-Olkin was 0.90 and Bartlett tests of sphericity was significant. These values reflected the sample adequacy and suitability for running factor analysis. Results show that two well defined factors were developed. Items having factor loading of 0.45 or more than 0.45 on two or more than two factors and those having less than 0.45 factor loading on all factors were discarded while items having factor loading of 0.45 or more than 0.45 on no more one factor were retained. Multiple criteria were used to finalize the number of factors. One of them is the eigenvalue which is a good criterion for identifying a factor according to the Kaiser criterion. A factor is selected if its eigenvalue is greater than one and vice versa. Results show that two factors had an eigenvalue greater than one. The screen plot showed inflection at three factors. Considering the Kaiser criterion of factor extraction two factors were retained with cumulative variance $60.33 \%$. Final factors were named as positive attitude toward research and negative attitude toward research. It was also ensured that each factor should contain at least three items. ${ }^{27}$ In the end 9 items were retained, of which 5 items were in factor positive attitude toward research with 0.84 alpha reliability and 4 items were in factor negative attitude toward research with 0.76 alpha reliability.

\section{Study II: Confirmatory Factor Analysis}

To confirm the factor structure of newly developed Attitude Toward Research Participation Scale confirmatory factor analysis was conducted on an independent sample.

\section{Objectives}

To confirm the factor structure attained through exploratory factor analysis.

\section{Sample}

The study sample consisted of 400 students including both men $(\mathrm{n}=150)$ and women $(\mathrm{n}=250)$ with age range of $18-$ $28(M=20.1, S D=6.9)$. Sample was selected from various universities of Punjab. Students from social and pure sciences both were given representation in the sample. Students who were admitted in university on the basis of sports or disability quota were excluded from the study.

\section{Instrument}

Nine items scale was used in this study which was selected on the basis of exploratory factor analysis.

\section{Procedure}

Online Google Forms was used to access the participants of study. Before the presentation of the test items, all

Table I The Factor Loading of 9 Items on Attitude Toward Research Participation Scale and on Two Factor Solution ( $\mathrm{N}=426)$

\begin{tabular}{|l|l|l|l|}
\hline \multirow{2}{*}{ Sr. } & \multirow{2}{*}{ Items } & Factors & II Negative Attitude Toward Research \\
\cline { 3 - 4 } & & I Positive Attitude Toward Research & -0.10 \\
\hline 1 & 10 & $\mathbf{0 . 7 6}$ & 0.02 \\
3 & 11 & $\mathbf{0 . 7 8}$ & 0.04 \\
4 & 12 & $\mathbf{0 . 7 8}$ & 0.09 \\
5 & 15 & $\mathbf{0 . 7 9}$ & -0.20 \\
6 & 17 & $\mathbf{0 . 7 0}$ & $\mathbf{0 . 7 4}$ \\
7 & 1 & -0.08 & $\mathbf{0 . 8 7}$ \\
8 & 2 & 0.10 & $\mathbf{0 . 8 0}$ \\
9 & 3 & 0.04 & $\mathbf{0 . 5 3}$ \\
\hline Eigenvalues & 19 & -0.26 & 1.38 \\
\hline \% of variance & & 4.05 & 15.34 \\
\hline Cumulative variance & 44.99 & 60.33 \\
\hline
\end{tabular}

Note: Bold values reflect significant loadings of items on their respective factors. 
participants read the informed consent and filled out the questionnaires only after they consented to participating in the study. It required only $2-3$ minutes to complete the scale.

\section{Results}

Findings of factor loading and model fit indices of CFA for attitude toward research participation scale is shown in Table 2 and Figure 1. For the estimation of structure and model fit indices the most preferred extraction method was used. On each factor structure factor analysis was conducted. For two factors confirmatory factor analysis yielded a good model fit to the data $\left[\chi^{2}(22)=59.65, p<\right.$ 0.001 , $\mathrm{RMSEA}=0.06, \mathrm{CFI}=0.97$, GFI $=0.97]$. The CFI and GFI value closer to 1 and RMSEA value closer to 0 were criteria used to assess model fit. As per criteria the value of chi square for CFA should be non-significant but it is nearly always significant due to large sample in social sciences. To resolve this issue the value of chi square is divided by degree of freedom and its value should be less
Table 2 Mean, Standard Deviation, Alpha Reliabilities and Descriptive of Attitude Toward Research Participation Scale, Curiosity and Exploration Inventory Scale (CEI) and Short Muslim Practices and Beliefs Scale $(\mathrm{N}=162)$

\begin{tabular}{|l|l|l|l|l|}
\hline Variables & \multicolumn{1}{|l|}{$\boldsymbol{M}$} & SD & Range & $\boldsymbol{\alpha}$ \\
\hline Positive ATRS & 18.06 & 4.48 & $5-25$ & 0.90 \\
Negative ATRS & 7.96 & 3.91 & $4-20$ & 0.88 \\
CEI & 33.72 & 7.43 & $16-49$ & 0.87 \\
SMPBS & 35.82 & 5.67 & $18-45$ & 0.86 \\
\hline
\end{tabular}

Abbreviations: ATRS, Attitude Toward Research Scale; CEI, Curiosity and Exploration Inventory; SMPBS, Short Muslim Practices and Beliefs Scale.

than 3. Our results showed that ratio of chi square and $d f$ for CFA was 2.71 which is in the range of the given criterion. The final model contained 9 items showing good model fit with 5 items in positive attitude toward research and 4 items in negative attitude toward research. As a result of CFA 9 items were selected with factor loading ranging from 0.63 to 0.81 .

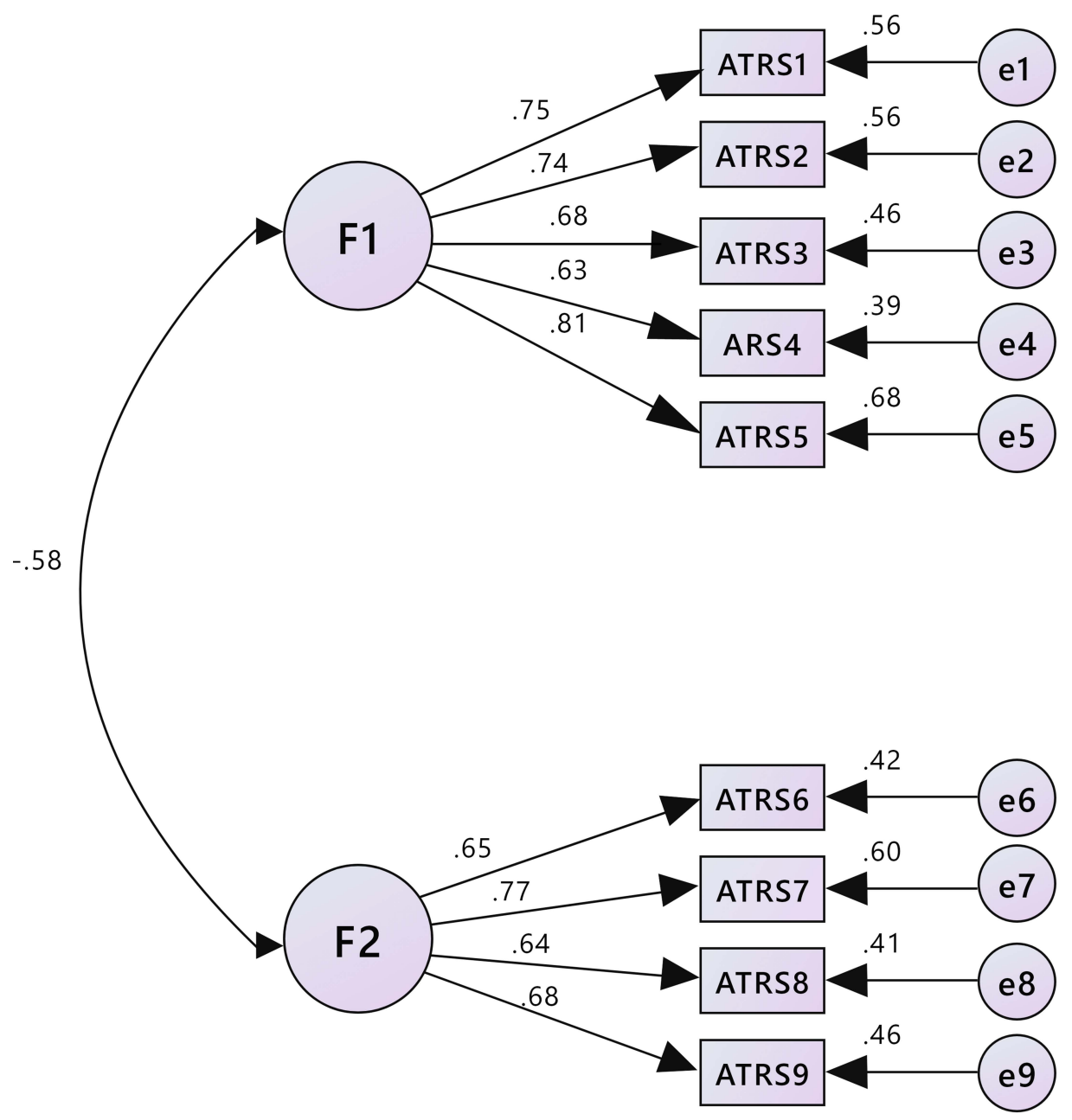

Figure I Measurement model fit of Attitude Toward Research Participation Scale. 


\section{Study III: Validation of Attitude Toward Research Participation Scale}

In study III, validation of attitude toward research scale was conducted. The relationship of Attitude Toward Research Participation Scale was checked with curiosity and religiosity.

\section{Sample}

The convenient sampling technique was used to select the sample of study which consisted of 162 students including both men $(\mathrm{n}=71)$ and women $(\mathrm{n}=91)$ with an age range of 17-27 $(M=19.5, S D=7.8)$ Sample was selected from various universities of Punjab. Students from social and pure sciences both were given representation in the sample. Students who were admitted in university on the basis of sports or disability quota were excluded from the study.

\section{Instruments}

In the present study the measures used as evidence of convergent and divergent validity of Attitude Toward Research Participation Scale are described below.

\section{Curiosity and Exploration Inventory (CEI)}

Curiosity and Exploration Inventory was used to measure the curiosity of participants. This scale consisted of seven items. The response format of this scale is a 7-point Likert-type scale ranging from 1 (strongly disagree) to 7 (strongly agree). This scale consists of two subscales named exploration and absorption. Exploration subscale include items 1, 3, 4, and 7 and Absorption subscale include items 2, 5, and 6. Item 4 is reversely coded. Total Cronbach's alpha reliability of scale was 0.80 . Cronbach's alpha reliability of exploration subscale was 0.74 and of absorption subscale was 0.73 . The scale has excellent model fit indices $($ chi square $/ \mathrm{df}=2.29$, GFI $=$ $0.92, \mathrm{CFI}=0.93$, RMSEA $=0.08)$.

\section{Short Muslim Practices and Beliefs scale}

This scale consisted of 9 items. This scale consisted of 2 sections named Muslim practices and Muslim beliefs. Muslim practices comprised 4 items with response format of 5-point Likert-type scale ranging from 1 (I never do this) to 5 (I always do this). Muslim beliefs comprised 5 items with response format of 5-point Likert-type scale ranging from 1 (strongly disagree) to 5 (strongly agree). There is no reversely coded item. Cronbach's alpha reliability of scale is 0.83 . The scale has good model fit. Sample item of the study are "I pray five times a day",
"The portrayal (picture, painting) of a human figure (such as a face) should not be allowed?"

\section{Procedure}

Online Google Forms was used to access the participants of study. Before the presentation of the test items, all participants read the informed consent and filled out the questionnaires only after they consented to participating in the study. Participants were assured about confidentiality of their information. Correct and authentic information was demanded from participants. Demographics were also included. It required only 15-20 minutes to complete the scale.

\section{Results}

Table 2 presents alpha reliability, mean, and standard deviation of scales used for the purpose of current study.

Table 3 shows the Pearson correlation between study variables. Results show that positive attitude toward research has significant negative correlation with negative attitude toward research $(r=-0.56, p s<0.001)$ and has positive correlation with curiosity $(r=0.25, p<$ $0.05)$ and non-significant correlation with religiosity $(r=$ $0.06, p=\mathrm{ns}$ ). Results show that negative attitude toward research has significant negative correlation with curiosity $(r=-0.18, p<0.05)$ and non-significant correlation with religiosity $(r=0.09, p=\mathrm{ns})$. These findings provided evidence for construct validity of the scale.

\section{Discussion}

The purpose of current study is construction and validation of the Attitude Toward Research Participation Scale for university students. All over the world there are many scales that have been developed to measure attitude toward research but there is no valid and reliable scale for students' attitude toward research participation. Participants from different areas of life have different attitude toward research participation so there was no reliable and valid scale to measure the attitude toward research participation.

Table 3 Pearson Correlation Among Study Variables $(\mathrm{N}=162)$

\begin{tabular}{|l|l|l|l|l|}
\hline Variables & $\mathbf{I}$ & $\mathbf{2}$ & $\mathbf{3}$ & $\mathbf{4}$ \\
\hline I. Positive ATRS & - & $-0.56^{* * * *}$ & $0.25^{*}$ & 0.06 \\
2. Negative ATRS & & - & $-0.18^{*}$ & 0.09 \\
3. CEI & & & - & $0.40^{* * *}$ \\
4. SMPBS & & & & - \\
\hline
\end{tabular}

Note: $* * * p<0.001$.

Abbreviations: ATRS, Attitude Toward Research Scale; CEI, Curiosity and Exploration Inventory; SMPBS, Short Muslim Practices and Beliefs Scale. 
Most of the researchers prefer to select university students as the sample of their study because the experiences of research participants regarding their participation in research highlight the significance of attitude toward research participation among university students. Therefore the purpose of present study was to develop a valid and reliable scale of the attitude toward research participation for students.

Three studies were included in this present research. In step 1 of study I, items were generated on the basis of interviews, expert opinion and previous literature. In step 2 , tryout study was conducted. Items generated in step 1 of Attitude Toward Research Participation Scale were administered. On the basis of response and feedback from the participant some items were deleted.

In step III, principal axis factoring was conducted to establish factor structure of Attitude Toward Research Participation Scale. To assess the data, exploratory factor analysis was run through oblique method. It is said that the oblique rotation method describes correlated factors while an orthogonal method tells us about unrelated factors so oblique rotation is better. In the present research, as all the constructs were correlated theoretical, we use the oblique rotation method. The items were retained with 0.45 or greater loading and conceptually relevant. ${ }^{26}$ Final 9 items were retained that were divided into two factors. The first factor measure the positive attitude of students toward participation in research. This factor is related to the usefulness, importance and appreciation. Second factor measure the negative attitude of students toward research participation. This factor is related to angry behavior and non-productive attitude toward research. Findings of the current study are in line with the previous literature that reflects the two dimensional attitude toward research and research participation. ${ }^{13,16}$

In study II two factor structure was confirmed that was obtained through EFA. Confirmatory factor analysis was run out on the Attitude Toward Research Participation Scale (see Table 2 and Figure 1). For factor analysis CFA provides hypothetical grounds so it is more powerful and it is considered as an important evidence of construct validity. In the present research two factor structure was finalized through CFA that was obtained through EFA and good model fit value was obtained for data with 9 items. This is highly valid and reliable scale which measure attitude toward research participation (see Table 4).

In study III the newly developed Attitude Toward Research Participation Scale was validated. To provide
Table 4 Items of the Scale

\begin{tabular}{|c|c|}
\hline Sr. No & Item \\
\hline I & $\begin{array}{l}\text { Whenever I participate in research, I honestly respond on } \\
\text { the research questionnaire. }\end{array}$ \\
\hline 2 & $\begin{array}{l}\text { I must complete the research questionnaire even if it is not } \\
\text { according to my interest. }\end{array}$ \\
\hline 3 & $\begin{array}{l}\text { Whenever I saw someone asking to others for filling their } \\
\text { research questionnaire, I also try to participate in it. }\end{array}$ \\
\hline 4 & $\begin{array}{l}\text { I think that we should participate in research (as participant) } \\
\text { because it is beneficial for researchers and society. }\end{array}$ \\
\hline 5 & $\begin{array}{l}\text { I appreciate those people who put their energy in } \\
\text { conducting research. }\end{array}$ \\
\hline 6 & I fill the research questionnaire randomly without reading it. \\
\hline 7 & $\begin{array}{l}\text { Whenever I participate in any research as a part of sample, } \\
\text { I feel that I wasted my time. }\end{array}$ \\
\hline 8 & $\begin{array}{l}\text { If someone ask me to fill a research questionnaire, } \\
\text { I become angry }\end{array}$ \\
\hline 9 & $\begin{array}{l}\text { If someone ask me to fill a research questionnaire I directly } \\
\text { refuse to do it. }\end{array}$ \\
\hline
\end{tabular}

a strong evidence of divergent validity for the Attitude Toward Research Participation Scale, it was hypothesized on the basis of literature review that the Short Muslims Practices and Believes Scale can be used as an evidence of divergent validity. So it is proved through findings that the Attitude Toward Research Participation Scale has nonsignificant relation with the Short Muslims Practices and Belief Scale. Religiosity is combination of religious belief and practice and logically and theoretically it does not share any conceptual overlap with the attitude toward research. Positive correlation of curiosity with positive attitude toward research participation and negative correlation of curiosity with negative attitude toward research provided evidence for the convergent validity of scale. It is consistently been proved that curiosity triggers a person to get involved in new and novel tasks so that a person may be able to know about something. ${ }^{27,28}$ Though curiosity is not yet explored with the attitude toward research participation, it is found to be correlated with attitude toward research, helping behavior, extroversion and agreeableness. ${ }^{29,30}$ These findings indirectly provide the support for current findings.

\section{Conclusion}

It is concluded that the newly developed Attitude Toward Research Participation Scale is a reliable and valid tool to 
measure positive and negative attitude of university students toward research. Findings of current study provided evidence of content and factorial validity. Moreover correlation with curiosity and religiosity provided convergent and discriminant validity evidence respectively.

\section{Limitations and Future Recommendation}

Unequal sample distribution of men and women is an important limitation of current study. Most of the students in Pakistani universities are female. For instance if there are 100 girls in a class then maximum ten will be boys except in IT or engineering departments. Moreover unequal representation of education and marital status can confound the findings. It is recommended that future researchers should try to ensure equal representation of demographic variables so that better generalizability and internal validity can be ensured.

Convenient sampling is also a limitation of the current study. Initially it was decided to opt for random sampling but due to the COVID intense situation in the area, classes were again shifted into online mode therefore it was not feasible to collect the data in the given time through random sampling. Therefore a convenient sampling technique was used.

The generalizability of this study is also limited as the sample was selected from some cities of Punjab, so future researchers must conducted their studies on larger samples to increase external validity. For the sake of validation only curiosity and religiosity were taken as the evidence of validity. In order to strengthen the validity of the scale it is suggested that future researches should be conducted with multiple evidences for validity. For instance personality traits and the previous experience of participants about research can increase the validity of the scale.

\section{Practical Implications of the Present Study}

The present scale is validated for attitude toward research participation in students, so we can use it to measure students attitude while conducting any research or survey to know that either the student participants respond correctly on research questionnaire or not. It can be used as a screening tool for the selection of participants for research. Furthermore on the basis of this scale students having negative attitude toward research can be guided and and their misconceptions can be eliminated. Student awareness programs can be launched so that students can be guided that their participation means a lot for the authenticity and accuracy of findings and ultimately the welfare of society. As the scale is in English language and does not have any direct cultural connotation/cultural biasness, therefore it can be applied and validated for other than Pakistani populations.

\section{Disclosure}

The authors report no conflicts of interest in this work.

\section{References}

1. Swindoll CR. Quotable quotes; 2012. Available from: http://www. goodreads.com/quotes/267482-the-longer-i-live-the-more-i-realizetheimpact. Accessed July 2, 2013.

2. Hussain T, Ch Q. A study on attitude towards research among technology education students in Pakistan. Bull Educ Res. 2016;38 (2):113-122.

3. Cameron P, Pond GR, Xu RY, Ellis PM, Goffin JR. A comparison of patient knowledge of clinical trials and trialist priorities. Curr Oncol. 2013;20(3):193-205.

4. Ohmann C, Deimling A. Attitude towards clinical trials: results of a survey of persons interested in research. Inflamm Res. 2004;53(2): S142-7.

5. Munir N, Bolderston A. Perceptions and attitudes toward conducting research: a nuclear medicine student perspective. J Med Imaging Radiat Sci. 2009;40(4):183-189.

6. Oguan FE Jr, Bernal MM, Pinca MC. Attitude and anxiety towards research, its influence on the students' achievement in the course. Asian J Manag Sci Educ. 2014;3(4):165-172.

7. Papanastasiou EC. Factor structure of the attitudes toward research scale. Stat Educ Res J. 2005;4(1):16-26.

8. Papanastasiou EC. Revised-Attitudes toward Research Scale (R-ATR); A first look at its psychometric properties. J Res Educ. 2014;24(2):146-159.

9. Abun D. The attitude of graduate students toward research and their intention to conduct research in the future. Available from: SSRN 3807893; March 19, 2021.

10. Habineza F. An exploratory survey of undergraduate's students attitudes towards research in INES-Ruhengeri in Rwanda. Int Educ Appl Sci Res J. 2018;3(3):1-5.

11. Heretick DM, Tanguma J. Anxiety and attitudes toward statistics and research among younger and older nontraditional adult learners. J Contin High Educ. 2021;69(2):87-99. doi:10.1080/07377363.2020.1784690

12. Imran SS, Nazir M, Dar W, et al. Attitude towards research among undergraduate and postgraduate medical students. Biomedica. 2019;35(4):239-243.

13. Landicho CJ. Research attitudes, motivations, and challenges of STEM education researchers. Int J Technol Educ. 2020;3(1):49-61. doi:10.46328/ijte.v3i1.21

14. Sabzwari S, Kauser S, Khuwaja AK. Experiences, attitudes and barriers towards research amongst junior faculty of Pakistani medical universities. BMC Med Educ. 2009;9(1):1-7. doi:10.1186/1472-69209-68

15. Butt IH, Shams JA. Master in education student attitudes towards research: a comparison between two public sector universities in Punjab. South Asian Stud. 2020;28(1):97-105.

16. Howe N, Giles E, Newbury-Birch D, McColl E. Systematic review of participants' attitudes towards data sharing: a thematic synthesis. J Health Serv Res Policy. 2018;23(2):123-133. doi:10.1177/13558 19617751555 
17. Hate K, Meherally S, Shah More N, et al. Sweat, skepticism, and uncharted territory: a qualitative study of opinions on data sharing among public health researchers and research participants in Mumbai, India. J Empir Res Hum Res Ethics. 2015;10(3):239-250. doi:10.1177/1556264615592383

18. Jao I, Kombe F, Mwalukore S, et al. Research stakeholders' views on benefits and challenges for public health research data sharing in Kenya: the importance of trust and social relations. PLoS One. 2015;10(9):e0135545. doi:10.1371/journal.pone.0135545

19. Cheah PY, Tangseefa D, Somsaman A, et al. Perceived benefits, harms, and views about how to share data responsibly: a qualitative study of experiences with and attitudes toward data sharing among research staff and community representatives in Thailand. J Empir Res Hum Res Ethics. 2015;10(3):278-289. doi:10.1177/1556264615592388

20. Manhas KP, Page S, Dodd SX, et al. Parental perspectives on consen for participation in large-scale, non-biological data repositories. Life Sci Soc Policy. 2016;12(1):1-3.

21. Shaukat S, Siddiquah A, Abiodullah M, Akbar RA. Postgraduate students' attitudes towards research. Bull Educ Res. 2014;36(1):111-122.

22. Al Furaikh S, Al Omairi B, Ganapathy T. A cross-sectional survey on nursing students' attitude towards research. J Health Specialties. 2017;5 (4): 185 .
23. Walport M, Brest P. Sharing research data to improve public health. Lancet. 2011;377(9765):537-539.

24. Walker DA. A confirmatory factor analysis of the attitudes toward research scale. $M L R V .2010 ; 36(1): 18-27$.

25. Siamian H, Mahmoudi R, Habibi F, Latifi M, Zare-Gavgani V. Students' attitudes towards research at Mazandaran University of Medical Sciences in 2015. Mater Sociomed. 2016;28(6):468.

26. Spyrou E. Curiosity saves the researcher. Nat Energy. 2021;6(1):6.

27. Dennis BK. Understanding participant experiences: reflections of a novice research participant. Int $J$ Qual Methods. 2014;13 (1):395-410.

28. Ye S, Ng TK, Yim KH, Wang J. Validation of the Curiosity and Exploration Inventory-II (CEI-II) among Chinese university students in Hong Kong. J Pers Assess. 2015;97(4):403-410.

29. AlMarri TS, Oei TP, Al-Adawi S. The development of the short Muslim practice and belief scale. Ment Health Relig Cult. 2009;12 (5):415-426.

30. Arnone MP, Small RV, Chauncey SA, McKenna HP. Curiosity, interest and engagement in technology-pervasive learning environments: a new research agenda. Educ Technol Res Devel. 2011;59 (2):181-198.
Psychology Research and Behavior Management

\section{Publish your work in this journal}

Psychology Research and Behavior Management is an international, peer-reviewed, open access journal focusing on the science of psychology and its application in behavior management to develop improved outcomes in the clinical, educational, sports and business arenas. Specific topics covered in the journal include: Neuroscience, memory and decision making; Behavior modification and management; Clinical

\section{Dovepress}

applications; Business and sports performance management; Social and developmental studies; Animal studies. The manuscript management system is completely online and includes a very quick and fair peer-review system, which is all easy to use. Visit http://www. dovepress.com/testimonials.php to read real quotes from published authors. 